\title{
An evaluation of the AutoAnalyzer SMA-4
}

\author{
T. R. J. LAPPIN, A. LAMONT, AND M. G. NELSON \\ From the Department of Clinical Pathology, Royal Victoria Hospital, Belfast, Northern Ireland
}

SYNOPSIS The Technicon AutoAnalyzer SMA-4 has been systematically evaluated. Carry-over from the sample cups was found to be within an acceptable range. The precision and accuracy of the four parameters determined by the instrument have been investigated. The haemoglobin results were found to be accurate. There was good agreement with leucocyte counts performed on the model A Coulter electronic cell counter. After certain modifications had been made in the manifold, satisfactory degrees of accuracy were also obtained for the erythrocyte counts. Although the determination of the haematocrit by conductance is influenced by a variety of factors, the mean coefficient of variation was found to be $0.83 \%$ and $95 \%$ of the results agreed within $\pm 2 \%$ of those obtained by the microhaematocrit centrifugation method.

A logistic assessment of the SMA-4 when it was put into routine use indicated the need to select blood samples without excess anticoagulant, to calibrate the instrument before each run, to test for instrumental drift, to use a rapid method of correcting stoppages, and, if concurrent reporting is carried out, to employ the part-time services of a second operator. The presence of dust in the environment was found to have a deleterious effect on both the mechanical and electronic components of the system requiring preventive maintenance. It should be possible, by interfacing an analogue-digital converter and automatic punch, to produce data compatible with records.

There is a considerable body of evidence which shows an exponential increase in the demand for the services of the hospital laboratory and little sign of any slowing. The resulting pressure has necessitated simplifying work or replacing manual by automated methods wherever possible. Among the available items of scientific laboratory equipment many are based on the continuous-flow analytical system. Such equipment was originally designed to automate specific single determinations but has been readily adapted for multichannel analysis.

In haematology the introduction of the Technicon AutoAnalyzer SMA-4 was a significant advance and was so named because it determined the four basic parameters, the haemoglobin, the haematocrit, the red, and the white cell counts by a process of sequential multiple analysis. This equipment can be converted into an SMA-7 by attaching a calculator which derives the MCV, the MCHC, and the MCH.

Previous studies had established the scientific basis for the use of multichannel equipment in haematology. Sturgeon and McQuiston (1965) reported on a two-channel AutoAnalyzer for haemoglobin and red cell determinations while Kernen, Wurzel, and Okada (1961) evaluated the conductance

Received for publication 31 May 1968. method of measuring the haematocrit. Gochman, Negersmith, and Weschler (1966) described a programmer-controlled continuous flow system for the sequential determination of the haematocrit, haemoglobin concentration, and red and white cell counts.

Our purpose now is to report our evaluation of the SMA-4 and to describe certain modifications to the manifold which we had to introduce in order to achieve acceptable degrees of precision and accuracy before the equipment was put into routine use.

\section{APPARATUS}

The SMA-4 consists of the following modular component parts: a sampler, a proportioning pump, plastic tubing manifolds and glass helical mixing and phasing coils, a conductivity flow cell, a tubular flow cell colorimeter, a dual channel cell counter, a programmer, and a single pen recorder. The anticoagulated whole blood in the sample cup is mixed by twin paddles and an aliquot taken up by the sampler crook. This is then split by the 'sample splitter' into four streams. These pass along the plastic tubing manifolds and helical mixing and phasing coils to individual detecting devices for the haematocrit, haemoglobin, and cell count determinations. The output from each detector is monitored by the programmer and fed sequentially to the single pen recorder. The instrument operates at a rate of 60 samples per hour and the results 
are graphically recorded and immediately readable. Variations from the 'normal' may be visualized against the range for each sex, which is indicated on the precalibrated graph paper by a shaded zone.

Before each run the appropriate manifold leads are connected, the pump tops locked into position, the electrical circuits switched on, and the reagents are allowed to flow through the manifold for 10 minutes. When all the flowlines are running satisfactorily, as indicated by the bubble pattern, the calibration of the instrument is checked. The haematocrit channel is adjusted with two $\mathrm{KCl}$ solutions of 2.66 and $5.07 \mathrm{~g}$ per litre which correspond to haematocrit readings of 50 and 19 respectively. The remaining channels are zeroed on the reagents. The instrument is then primed with eight whole blood samples from the previous day's run and calibrated with a whole blood reference standard. During a run the samples are divided into blocks of 10 separated by a physiological saline sample or by the reference standard separated from the blood samples by a blank on either side. This standard is used to detect and permit the correction of any instrumental drift. At the end of each run an alkaline detergent mixture of sodium hydroxide $(0.2 \mathrm{~N})$ and Tergitol NPX ( $1 \%)$ is run through the flowlines for 10 minutes. This is followed by a wash with distilled water for a further 10 minutes. The pump tops are then unclipped, the electrical circuit is switched off, and manifold tubing is clamped. A plastic cover should be placed over the programmer and recorder to protect these components from dust.

When the instrument was set up as described in the $\stackrel{\vec{F}}{\rightarrow}$ instructions issued by the Technicon Instruments Co. Ltd, the results obtained on three of the flowlines were $\bar{\sigma}$ found to be satisfactory but red cell counts were un- $\overline{\bar{C}}$ reliable. In an attempt to overcome this problem several $\mathbb{D}$ changes have been made to the original manifold of the red cell counting flow system. The four large reagent $c s$ tubes $(0.110$ in. diameter, $3.9 \mathrm{ml}$ per minute delivery), $\vec{\circ}$ which tended to give irregular delivery after prolonged use, were replaced by eight reagent tubes $(0.073$ in. $\vec{\omega}$ diameter, $2.0 \mathrm{ml}$ per minute delivery). The resample tube was connected to the tube containing the primary dilution? by means of an A2 glass fitting which prevents air bubbles from entering the resample aliquot. As a result any? irregularity in the primary red cell dilution due to air $\overrightarrow{.}$ bubbles is minimized.

The additional flow tubes introduced into the system necessitated the use of a second pump. Some of the remaining capacity of the pump was used to replace large $c$ pump tubes $(0 \cdot 110$ in. diameter) with smaller ones ( 0.073 in. diameter) in the white cell counting flow system. A flow diagram of the modified manifold is shown in $₹$ Figure 1.

The ultraviolet lamp provided with the instrument in order to accelerate the conversion of haemoglobin to cyanmethaemoglobin was found to be unnecessary if aO

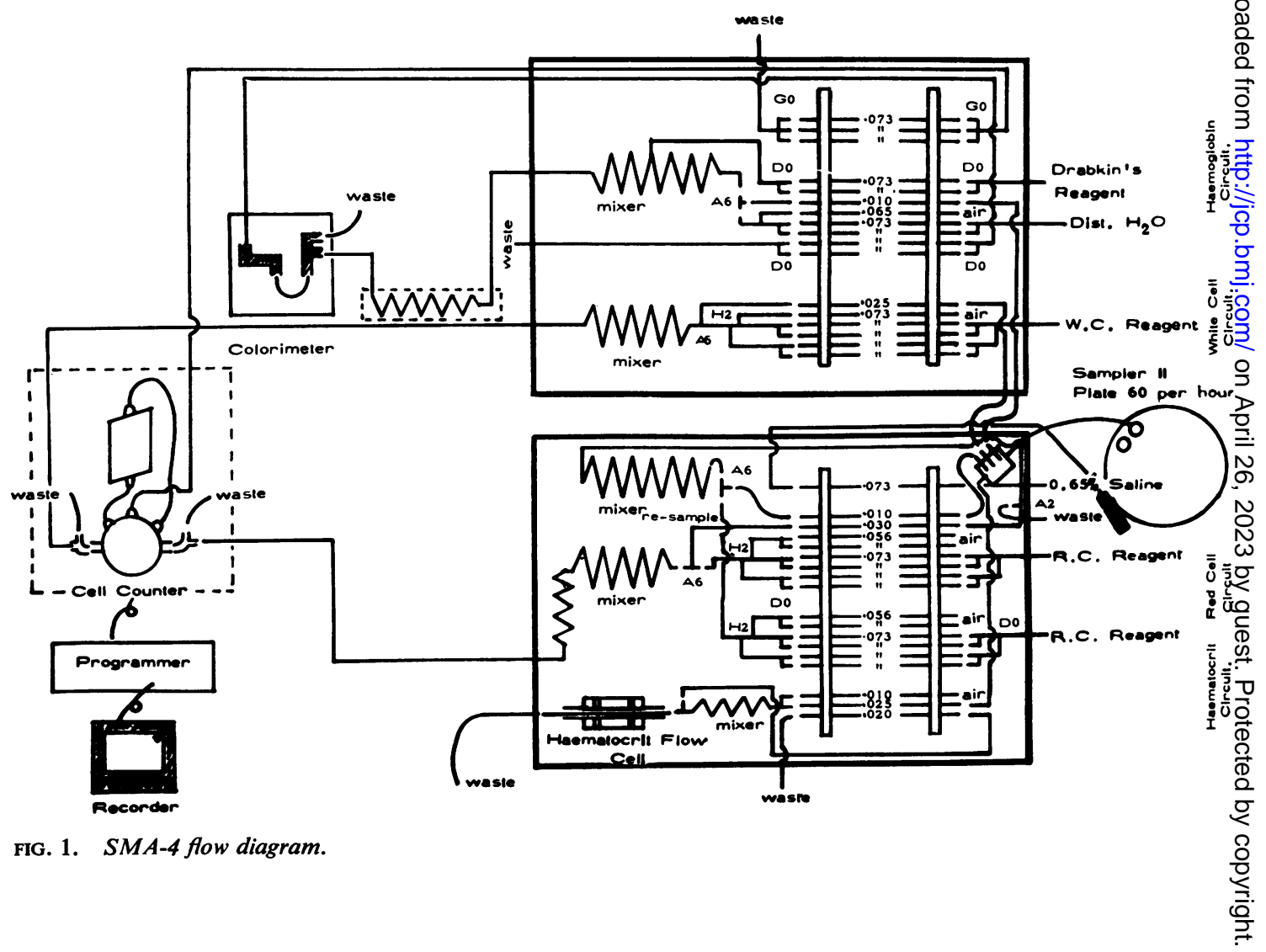


modified Drabkin's reagent, $p \mathrm{H} 7 \cdot 2$ (van Kampen and Zijlstra, 1961) was used.

\section{CARRY-OVER}

Basic to the scientific evaluation of an instrument which operates on the continuous flow analytical system is the need to determine the presence and degree of cross contamination. In the SMA-4 the most likely place for such interaction is at the point where carry-over from one sample cup to the next can occur. This was investigated using a radioisotope dilution method with ${ }^{131}$-albumin according to a technique recommended by Skentelbery and Neill (1968) which involves measuring the effect of samples of abnormally high values upon the result of a blank immediately following. The amount of carry-over from this cause was found to be less than $1.5 \%$, which is within an acceptable range.

\section{THE PRECISION OF THE RESULTS}

The precision of a measurement is the agreement between a series of determinations of the same quantity. In an instrument it can be regarded as a reflection of its mechanical consistency. It is usually determined by the repeated analysis of the same sample and then by calculating the standard deviation and the coefficient of variation.

Using the modified flow system, the precision of each of the four channels of the SMA-4 was studied by 20 or more replicate determinations on the same sample. The mean, range, standard deviation, and coefficient of variation were then calculated for each of the four parameters (Tables I to IV).

\section{THE ACCURACY OF THE RESULTS}

The accuracy of an analytical procedure is a measure of how close the observed value is to the 'true' value. Thus accuracy in the biochemical sense is more related to the design of the chemistry than to the mechanics of the measurement. In haematology the 'true' value is not absolute but can be derived by mathematical computation. To this end 100 blood samples were divided into two aliquots and submitted to analysis on the SMA-4 and by acceptable standard methods.

TABLE I

PRECISION OF SMA-4 HAEMATOCRIT READINGS ${ }^{1}$

\begin{tabular}{|c|c|c|c|c|c|c|c|}
\hline & Readi & & & & & & \\
\hline $\begin{array}{l}\text { Number } \\
\text { Mean } \\
\text { Maximum } \\
\text { Minimum } \\
\text { Standard deviation } \\
\text { Coefficient of variation }\end{array}$ & $\begin{array}{l}20 \\
14 \cdot 40 \\
15 \cdot 0 \\
14 \cdot 0 \\
0 \cdot 30 \\
2 \cdot 08\end{array}$ & $\begin{array}{l}20 \\
23 \cdot 87 \\
24 \cdot 5 \\
23 \cdot 5 \\
0 \cdot 32 \\
1 \cdot 34\end{array}$ & $\begin{array}{l}20 \\
29 \cdot 60 \\
30 \cdot 0 \\
29 \cdot 0 \\
0 \cdot 31 \\
1.04\end{array}$ & $\begin{array}{l}22 \\
37 \cdot 00 \\
37 \cdot 0 \\
37 \cdot 0 \\
0 \cdot 00 \\
0.00\end{array}$ & $\begin{array}{l}20 \\
44 \cdot 00 \\
44 \cdot 0 \\
44 \cdot 0 \\
0.00 \\
0.00\end{array}$ & $\begin{array}{l}20 \\
47 \cdot 83 \\
48 \cdot 5 \\
47 \cdot 5 \\
0 \cdot 29 \\
0 \cdot 69\end{array}$ & $\begin{array}{l}20 \\
53.20 \\
54.0 \\
53.0 \\
0.33 \\
0.63\end{array}$ \\
\hline
\end{tabular}

'Percentages.

TABLE II

PRECISION OF SMA-4 WHITE CELL COUNTER ${ }^{1}$

Reading

\begin{tabular}{|c|c|c|c|c|c|c|c|}
\hline $\begin{array}{l}\text { Number } \\
\text { Mean } \\
\text { Maximum } \\
\text { Minimum } \\
\text { Standard deviation } \\
\text { Coefficient of variation }\end{array}$ & $\begin{array}{l}20 \\
3 \cdot 32 \\
3 \cdot 5 \\
3 \cdot 1 \\
0 \cdot 11 \\
3 \cdot 23\end{array}$ & $\begin{array}{l}20 \\
4 \cdot 32 \\
4 \cdot 5 \\
4 \cdot 1 \\
0 \cdot 14 \\
3 \cdot 13\end{array}$ & $\begin{array}{l}20 \\
6 \cdot 25 \\
6 \cdot 5 \\
6 \cdot 1 \\
0 \cdot 13 \\
2 \cdot 11\end{array}$ & $\begin{array}{l}22 \\
6.97 \\
7 \cdot 2 \\
6 \cdot 8 \\
0 \cdot 12 \\
1 \cdot 65\end{array}$ & $\begin{array}{l}20 \\
8 \cdot 14 \\
8 \cdot 5 \\
7 \cdot 6 \\
0 \cdot 24 \\
2 \cdot 96\end{array}$ & $\begin{array}{l}20 \\
9 \cdot 66 \\
10 \cdot 0 \\
9 \cdot 5 \\
0 \cdot 19 \\
2 \cdot 00\end{array}$ & $\begin{array}{l}20 \\
22 \cdot 40 \\
23 \cdot 0 \\
21 \cdot 8 \\
0.43 \\
1.93\end{array}$ \\
\hline
\end{tabular}

${ }^{1}$ Cells $\times 10^{3}$ per c mm

TABLE III

PRECISION OF SMA-4 HAEMOGLOBINOMETRY ${ }^{1}$

Reading

\begin{tabular}{|c|c|c|c|c|c|c|c|}
\hline $\begin{array}{l}\text { Number } \\
\text { Mean } \\
\text { Maximum } \\
\text { Minimum } \\
\text { Standard deviation } \\
\text { Coefficient of variation }\end{array}$ & $\begin{array}{l}20 \\
6 \cdot 17 \\
6 \cdot 3 \\
6 \cdot 1 \\
0 \cdot 06 \\
0 \cdot 92\end{array}$ & $\begin{array}{l}20 \\
8 \cdot 01 \\
8 \cdot 1 \\
8 \cdot 0 \\
0 \cdot 03 \\
0 \cdot 41\end{array}$ & $\begin{array}{l}20 \\
9 \cdot 20 \\
9 \cdot 3 \\
9 \cdot 1 \\
0 \cdot 06 \\
0 \cdot 66\end{array}$ & $\begin{array}{l}22 \\
12 \cdot 45 \\
12 \cdot 5 \\
12 \cdot 3 \\
0 \cdot 06 \\
0 \cdot 48\end{array}$ & $\begin{array}{l}20 \\
14 \cdot 53 \\
14 \cdot 7 \\
14 \cdot 5 \\
0 \cdot 06 \\
0 \cdot 40\end{array}$ & $\begin{array}{l}20 \\
15 \cdot 42 \\
15 \cdot 5 \\
15 \cdot 3 \\
0 \cdot 08 \\
0 \cdot 53\end{array}$ & $\begin{array}{l}20 \\
16 \cdot 11 \\
16 \cdot 2 \\
16 \cdot 0 \\
0.06 \\
0 \cdot 38\end{array}$ \\
\hline
\end{tabular}

${ }^{1} \mathrm{~g}$ per $100 \mathrm{ml}$ blood. 
TABLE IV

PRECISION OF SMA-4 RED CELL COUNTER ${ }^{1,2}$

\begin{tabular}{|c|c|c|c|c|c|c|c|}
\hline & Readi & & & & & & \\
\hline $\begin{array}{l}\text { Number } \\
\text { Mean } \\
\text { Maximum } \\
\text { Minimum } \\
\text { Standard deviation } \\
\text { Coefficient of variation }\end{array}$ & $\begin{array}{l}20 \\
2 \cdot 12 \\
2 \cdot 2 \\
2 \cdot 0 \\
0 \cdot 08 \\
3 \cdot 62\end{array}$ & $\begin{array}{l}20 \\
3 \cdot 04 \\
3 \cdot 2 \\
2.9 \\
0 \cdot 07 \\
2 \cdot 24\end{array}$ & $\begin{array}{l}22 \\
4 \cdot 38 \\
4 \cdot 5 \\
4 \cdot 3 \\
0 \cdot 07 \\
1 \cdot 52\end{array}$ & $\begin{array}{l}20 \\
5 \cdot 10 \\
5 \cdot 2 \\
5 \cdot 0 \\
0 \cdot 10 \\
1 \cdot 91\end{array}$ & $\begin{array}{l}20 \\
5 \cdot 30 \\
5 \cdot 4 \\
5 \cdot 1 \\
0 \cdot 12 \\
2 \cdot 29\end{array}$ & $\begin{array}{l}20 \\
5 \cdot 66 \\
5 \cdot 8 \\
5 \cdot 5 \\
0 \cdot 11 \\
2 \cdot 02\end{array}$ & $\begin{array}{l}20 \\
6 \cdot 74 \\
7 \cdot 0 \\
6 \cdot 5 \\
0 \cdot 20 \\
2 \cdot 99\end{array}$ \\
\hline
\end{tabular}

1 Cells $\times 10^{\circ}$ per cmm.

'Using the original manifold for red cell counting, coefficients of variation of $5 \cdot 26,5 \cdot 18$, and $3 \cdot 57 \%$ were found for three bloods, the means of which were $5 \cdot 30,4 \cdot 57$, and $4 \cdot 31 \times 10^{6}$ cells per cmm respectively

TABLE V

COMPARISON OF RESULTS WITH SMA-4 AND OTHER METHODS

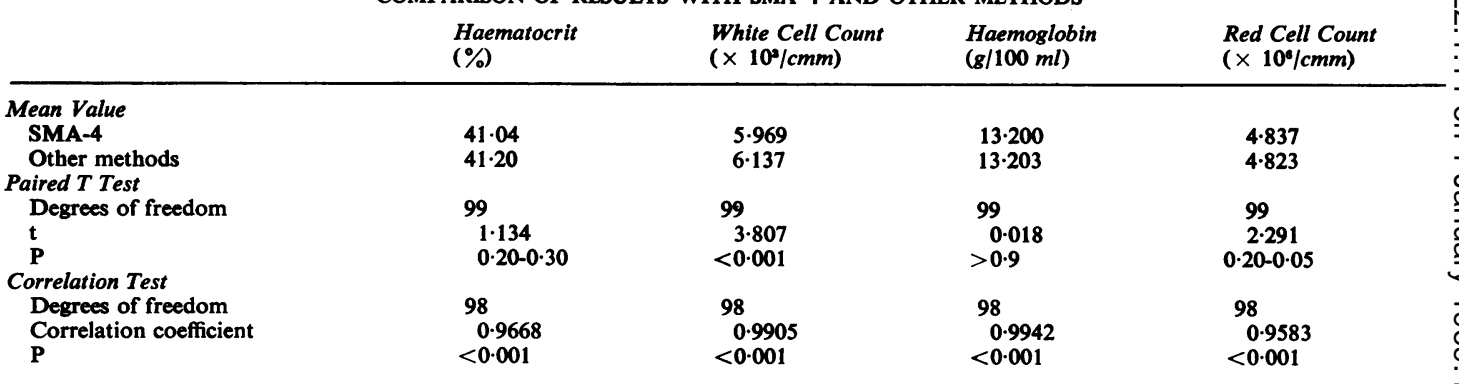

The methods chosen for comparison were as follows. The haemoglobin content was determined as cyanmethaemoglobin at $540 \mathrm{~m} \mu$ in an Optica CF 4 spectrophotometer which had been calibrated against the cyanmethaemoglobin reference standard marketed by British Drug Houses Ltd, which conforms to the ICSH International Reference Standard. A Coulter electronic cell counter model A was used for white cell counts by the method of Richar and Breakell (1959) and for red cell counts by the method of Brecher, Schneiderman, and Williams (1956). The packed cell volume was determined by the microhaematocrit centrifugation method (Hawksley) and the results were read on the standard reader. Each pair of results was then subjected to statistical analysis by calculating the regression equation and the correlation coefficient (Table V).

Table $\mathrm{V}$ shows that there is no significant $(\mathrm{P}>$ 0.05 ) average difference between the results of the two methods for haemoglobin concentration $(t=$ 0.0184 , degrees of freedom $=99, \mathrm{P}>0.9$ ) and for haematocrit $(t=1 \cdot 134$, degrees of freedom $=99$, $0.3>P>0.2$ ). However, a non-significant value of $t$ is insufficient proof of accuracy.

If two methods give identical results then the results from the standard method $(y)$ must be strongly associated, in a positive sense, with the corresponding results of the SMA-4 $(x)$. This was tested by calculating the correlation coefficient (r). Furthermore, for $100 \%$ accuracy, the relationship between $y$ and $x$ should be of the form $y=x$. For haemoglobin we found: (1) $r=0.9942$, degrees of freedom $=98, \mathrm{P}<0.001$, and (2) $y=1.003 x$ 0.04 (standard deviation from regression $S_{y \cdot x}=0$ $0 \cdot 2839$ ). For haematocrit we found: (1) $r=0.9668 \AA$ degrees of freedom $=98, \mathrm{P}<0.001$, and (2) $y=$ $0.9205 x+3.41$ (standard deviation from regression $\mathrm{S}_{y \cdot x}=1 \cdot 352$ ).

The results of white cell counting gave a significan value for $t(t=3 \cdot 807$, degrees of freedom $=99$ $P<0.001$ ). Figure 3 shows that there was a difference? of 0.7 to $1.2 \times 10^{3}$ cells per cmm in 13 of the 1009 samples. The mean difference between the two methods was $0.168 \times 10^{3}$ cells per cmm. For whiteo cell counting we found: (1) $\mathbf{r}=0.9905$, degrees of freedom $=98, \mathrm{P}<0.001$ and (2) $y=1.003 x+0.1509$ (standard deviation from regression $S_{y \cdot x}=0 \cdot 1316$ )

For red cell counting the results yield a significante. difference $(t=2.291$, degrees of freedom $=99, \mathrm{~N}$ $0.05>P>0.02)$. However, there is a very smalP difference between the means of the two red celis counting methods, and there is strong positives correlation. For red cell counting we found: (1) $r=$ 0.9583 , degrees of freedom $=98, \mathrm{P}<0.001$ and (2) $y=0.9902 x+0.034$ (standard deviation from regression $S_{y \cdot x}=0.1738$ ).

Scatter graphs and regression equations are shown in Figures 2 to 5.

\section{DISCUSSION}

It is essential during the course of the technicat 


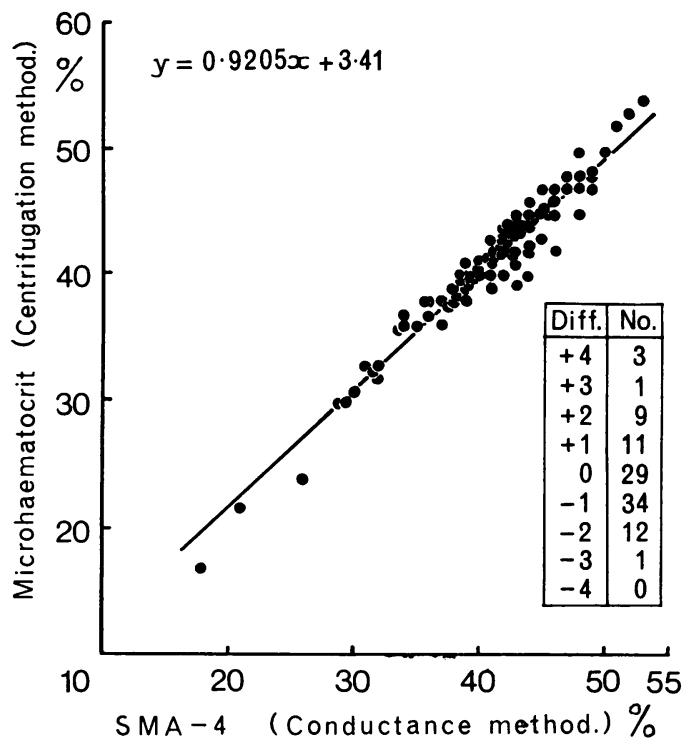

FIG. 2. Comparison of duplicate haematocrit determinations.

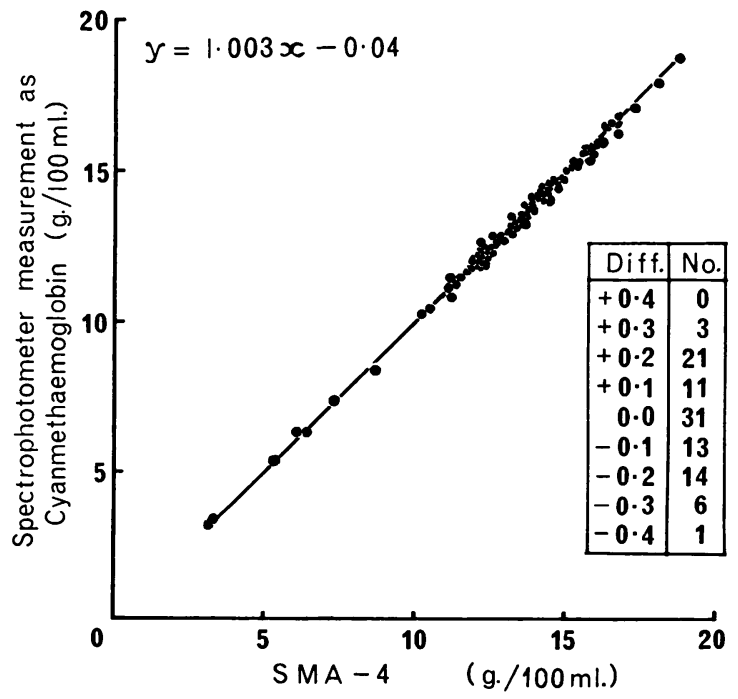

FIG. 4. Comparison of duplicate haemoglobin determinations.

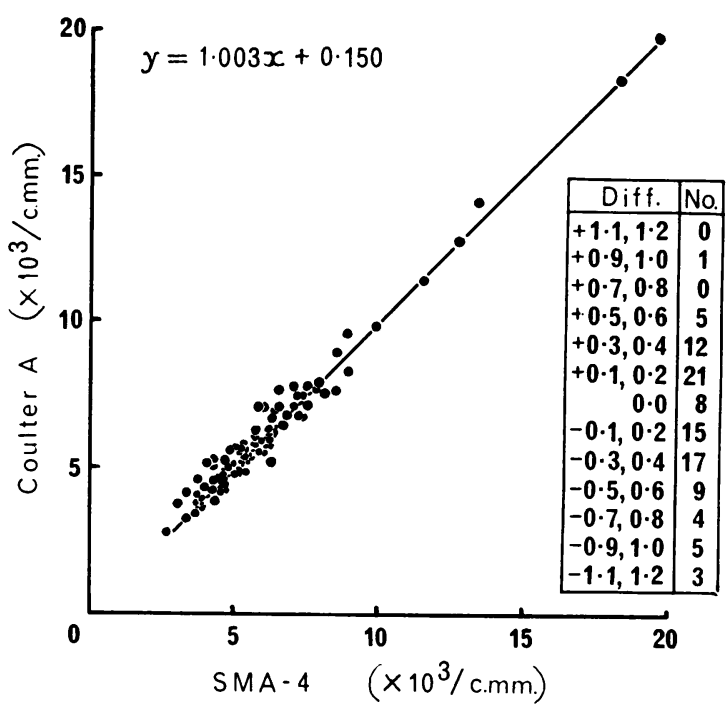

FIG. 3. Comparison of duplicate leucocyte determinations.

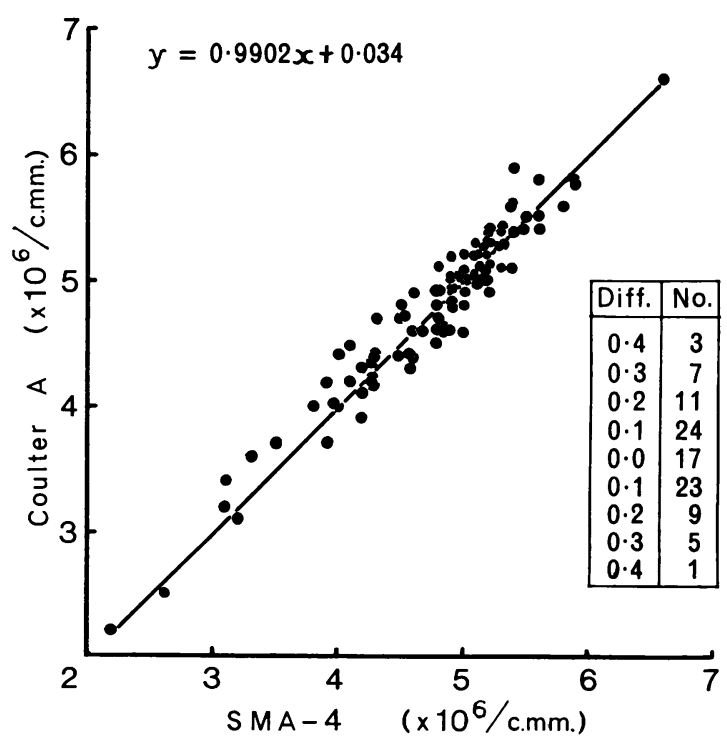

FIG. 5. Comparison of duplicate erythrocyte determinations. 
evaluation of analytical equipment which works on the continuous flow system to ascertain whether there is any carry-over from one sample cup to another. Of the methods available the one using radioiodinated albumin recommended by Skentelbery and Neill (1968) is both neat and precise. When applied to the SMA-4 the carry-over was found to be less than $1.5 \%$, which is an acceptable figure.

The determination of haemoglobin by an automated cyanmethaemoglobin method using a single channel AutoAnalyzer has already been favourably reported from this centre by Nelson (1967). It was not surprising, therefore, to find that the haemoglobin determination which was carried out by a similar method on the SMA-4 was a precise and accurate parameter. Table III shows that the coefficients of variation, which were in the range 0.38 to $0.92 \%$, tend in general to decrease with increasing concentration of haemoglobin, indicating that the determination is more accurate for higher haemoglobin values. This finding is in agreement with that of Sturgeon and McQuiston (1965).

On the SMA-4 the haematocrit is estimated by a conductance method which assumes a normal content and distribution of both plasma protein and electrolyte in the sample. Since conductivity is a function of ionic concentration, the haematocrit estimation is significantly altered if the concentration of dipotassium EDTA anticoagulant is much greater than $2 \mathrm{mg}$ per millilitre of blood (Lappin and Lamont, 1968) (Fig. 6). This effect of excess anticoagulant has also been reported by Davis, Bresland, and Green (1966) who systematically evaluated the effect of a number of parameters on the haematocrit values obtained by the conductance method. This study showed that the factors most likely to influence the haematocrit were high protein concentration, high white cell counts, and electrolyte concentration.

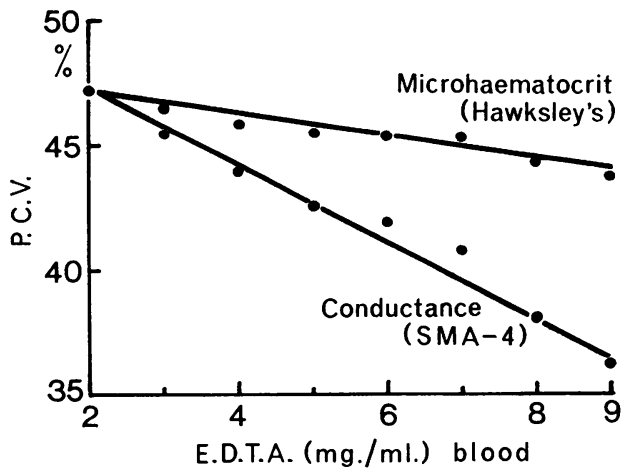

FIG. 6. Effect of concentration of EDTA anticoagulant on the PCV determination.
Furthermore, it was found that 'variation in plasmao electrolytes up to $150 \mathrm{mE} /$ litre, leucocyte counts up to 30,000 per $\mathrm{mm}^{3}$, and protein concentration up too $9 \mathrm{~g} \%$ did not influence the results'. Davis et al alsoo reported that $86 \%$ of 500 samples gave results which were within $\pm 2 \%$ of the microhaematocrit centri- $-\bar{s}$. fugation method. Our studies confirm those of Davis and his colleagues. Furthermore, we wouldo agree with their general conclusion that the con-s ductance method appears to be satisfactory for? screening purposes.

Cell counting on the SMA-4 is achieved by a dualo channel module with a single optical system fos? alternate determination of leucocytes and erythro-in cytes. A narrow beam of light is projected through the flow cell onto a dark field disc. When a cell interrupts the beam, the resulting scattered light $\vec{b}$ passes around the disc and is focused onto a photo-? multiplier tube, where an electrical pulse is generated for each interrupting particle. Coincidence occurs when one cell completely obscures another while⿳亠丷厂巾 passing the dark field disc but this is intrinsically corrected by the calibration on the chart paper $\vec{\theta}$ Filtered leucocyte diluent $(3 \%$ acetic acid, $1 \%$ Tergitol), as recommended by the manufacturer, and isotonic phosphate-buffered saline $(p \mathrm{H} \mathrm{7.4)}$ with Brij.-35 detergent additive for erythrocyte counting were used.

For white cell counting, the mean coefficient of variation for the SMA-4 was found to be $2.43 \%$ 은 This is comparable with the mean value of $2.5 \%$ obtained on a model A Coulter counter by Nelson and Carville (1962) and with that of Richar and Breakell (1959) who found that the standard error was between 1.39 and $4.02 \%$. Richar and Breake believe that their data indicate that the same celb population is counted in the Coulter counter and in? the standard haemocytometer. For white cell count 8 ing our results on the SMA-4 and the Coultep counter show good agreement. Any variations caro be partly explained by the different threshold settings which result in different sensitivities of the two detection systems, to populations of particles of varying size and to different reagent backgroun $\Phi^{\$}$ counts. Differences may also arise due to the debriș from red cells, variation in size and shape of white् cells, and to varying degrees of coincidence.

Initially a number of red cell counts carried out on the SMA-4 were unacceptable and coefficients of variation ranged from $3 \cdot 6$ to $5 \cdot 3 \%$. The modifications? to the manifold which we have described haveo reduced the average coefficient of variation to $2.37 \%$ Using a similar optical detection system on an Auto 8 Analyzer red cell counter Sturgeon found an averag coefficient of variation of the same magnitude. For red cell counting on a Coulter counter, Nelson and 
Carville (1962) reported a mean coefficient of variation of $1.44 \%$ and Sturgeon and McQuiston (1965) values ranging from 1.5 to $4.0 \%$. The present study indicates that, using the improved manifold, the red cell counting of the SMA-4 produces both precise and reliable results. This is shown by the fact that only $4 \%$ of results from the SMA- 4 differed by more than $0.3 \times 10^{6}$ cells per $\mathrm{cmm}$ from those obtained on the Coulter cell counter.

However, satisfactory results obtained during the course of a specially organized scientific assessment are not necessarily a true reflection of the performance of an instrument when in routine use. Therefore, as the original study had been carried out under favourable conditions by experienced scientific and technical staff, the equipment was transferred to the routine service laboratory. Here it was placed in the hands of less skilled operators and subjected to a work load of some 200 samples per day. This logistic assessment has brought into clearer perspective a number of operational problems.

In the first instance it proved necessary to ensure that the blood samples did not contain excess EDTA anticoagulant. To prevent this we reduced the amount of anticoagulant in the $5 \mathrm{ml}$ sample containers from $2 \mathrm{mg}$ to $1.6 \mathrm{mg}$ per $\mathrm{ml}$ and only accepted for analysis those containers which had more than $4 \mathrm{ml}$ of blood.

Before each batch of tests approximately one hour is needed to start up the equipment, to run through the reagents and the blood primers for zeroing, and the standards for calibration. When the machine is operational a technician concurrently records the results directly from the graph on to a worksheet and detects faults in the system. Consequently the parttime services of a less experienced operator have proved to be necessary in order to mix the samples, fill the sampler plate, and carry out less skilled tasks.

It has been our experience that a fault will occur in the equipment at least once every day and it need hardly be stated that all such stoppages should be quickly corrected. The chief cause is mechanical blockage of the flowlines at certain critical points, mainly at the sample splitter. The number of stoppages due to this cause can be reduced but not eliminated by regularly washing the flowlines at the end of each run.

We have found the equipment to be particularly vulnerable to dust in the laboratory atmosphere and protection of the reagent containers from contamination by dust is necessary. Dust is also deleterious to the electrical components of the programmer, particularly the printed circuits and the micro switches. Preventive maintenance of the electronic components of the programmer at least once every two weeks is needed.
It is now generally recognized that, as a result of the increasing number of tests and their increasing automation, much more attention must be paid to ensuring that standards of accuracy and precision are not allowed to fall and that insidious variations in the machine's performance do not result in gradual deterioration in the quality of results. To this end we maintain two independent systems of quality control. We prepare our own blood cell working reference standard to check the precision and control the drift of the already calibrated instrument. In addition we also apply the cusum statistical method both to the haemoglobin and the haematocrit determinations.

The results obtained on the SMA-4 are graphically recorded on the chart and an individual set of results for one patient can be torn off for transfer to the ward or delivery to the physician. However, the large sheet of graph paper is not always compatible with patients' records and translation into digital form with subsequent transcription onto currently used record documents may be desirable. Concurrent recording, directly from the chart onto a worksheet or report document, is the most satisfactory method but requires the technician to observe the chart continually and to record the results. The introduction of an electronic analogue digital converter and some form of digital recorder would free the technician from the responsibility of carrying out these datahandling functions. It is for this reason that we are trying to develop, in conjunction with the instrument industry, a system which involves the interfacing of an analogue-digital converter, together with a linearizer and scaler to an automatic punch. The test results in digital form will then be punched onto an 80-column card for subsequent automatic reproduction on to the report document. The laboratory data can then be stored either on the punch card or transferred to the memory store of a computer.

The basic requirements of an automated analytical system are that the results should be precise, accurate, and free from carry-over, that the equipment should function at as high a speed as possible compatible with accuracy, and that the data should be automatically produced with the minimum of clerical work. At the same time the equipment should be mechanically and electronically reliable, and operate at an economic cost. The SMA-4 certainly meets most of these requirements. The ultimate test for the evaluation of any scientific equipment is how such equipment behaves when subjected to a large daily workload in a service laboratory. The fact that this equipment is in daily use in a hospital department of haematology is a measure of its acceptability.

We should like to thank Dr J. D. Merrett, Department of 
Medical Statistics, Queen's University, Belfast, for his help and advice.

\section{REFERENCES}

Brecher, G., Schneiderman, M., and Williams, G. Z. (1956). Amer. J. clin. Path., 26, 1439.

Davis, R. E., Bresland, R., and Green, R. (1966). Lab. Pract., 15, 1376.

Gochman, N., Negersmith, K. M., and Weschler, W. (1966). Autom. Analyt. Chem. 1, 115. yan Kampen, E. J., and Zijlstra, W. G. (1961). Clin. chim. Acta, 6, 538.

Kernen, J. A., Wurzel, H., and Okada, R. (1961). J. Lab. clin. Med., $57,635$.

Lappin, T. J. R., and Lamont A. (1968). J. clin. Path., 21, 114. Nelson, M. G., and Carville, J. (1962). Irish J. med. Sci., 447.

- (1967). J. clin. Path., 20, 671.

Richar, W. J., and Breakell, E. S. (1959). Amer. J. clin. Path., 31, 384.

Skentelbery, R. G., and Neill, D. W. (1968). Personal communication. Sturgeon, P., and McQuiston, D. T. (1965). Amer. J. clin. Path., 43, 517. 